\title{
PENERAPAN KONSEP GAMIFIKASI PADA E-LEARNING UNTUK PEMBELAJARAN ANIMASI 3 DIMENSI
}

\author{
Sitaresmi Wahyu Handani ${ }^{1}$, M. Suyanto ${ }^{2}$, Amir Fatah Sofyan ${ }^{3}$ \\ Magister Teknik Informatika, STMIK AMIKOM Yogyakarta \\ sita.handani@gmail.com ${ }^{1}$, yanto@amikom.ac.id ${ }^{2}, \underline{\text { amir@amikom.ac.id }}^{3}$
}

\begin{abstract}
ABSTRAK
Perkembangan industri kreatif khususnya bidang animasi 3D semakin luas. Seiring dengan perkembangan tersebut, kebutuhan sumber daya manusia untuk industri animasi pun semakin meningkat. Ada banyak cara untuk belajar animasi 3D, baik melalui pendidikan formal maupun non-formal. E-learning merupakan sistem pendidikan yang menggunakan aplikasi elektronik untuk mendukung pengembangan kegiatan belajar mengajar dengan media internet, intranet atau media jaringan komputer lain. Dengan adanya e-learning memungkinkan terjadinya proses pendidikan tanpa melalui tatap muka langsung dan pengembangan ilmu pengetahuan kepada pelajar atau mahasiswa bisa dilakukan dengan mudah. Salah satu cara untuk meningkatkan motivasi pelajar dari beberapa penelitian yang telah dilakukan adalah dengan menerapkan konsep gamifikasi. Gamifikasi merupakan proses menggunakan mekanisme atau aturan dalam game pada aktivitas non game dengan tujuan meningkatkan interaktivitas pengguna. Dalam menerapkan konsep gamifikasi ke dalam sistem pendidikan/e-learning diperlukan sebuah framework untuk menyusun desain game ke dalam sistem yang akan dibangun. MDA framework yang merupakan kependekan dari Mechanics, Dynamics, \& Aesthetics merupakan framework yang digunakan untuk desain sebuah game. Agar game desain yang disusun sesuai dengan karakter calon pengguna diperlukan sebuah analisa tentang beberapa tipe pengguna. Richard Bartle dalam penelitiannya mendefinisikan karakter pemain menjadi 4 tipe yaitu explorers, achievers, socializers, dan killers. Penerapan konsep gamifikasi ke dalam e-learning untuk mempelajari Animasi 3D menggunakan MDA framework dan menggabungkannya dengan teori yang dikemukakan oleh Richard Bartle merupakan salah satu inovasi dalam proses belajar Animasi 3D agar lebih interaktif.
\end{abstract}

Kata Kunci: Animasi 3D, e-learning, gamifikasi, MDA framework, Richard Bartle's Type

\section{PENDAHULUAN}

Animasi dalam bahasa Indonesia berasal dari kata "Animation". Animation berasal dari bahasa Yunani, anima, yang berarti "napas" dan napas identik dengan "hidup", hingga animasi secara sederhana adalah "memberi hidup pada sesuatu yang tidak hidup sebelumnya". Definisi lain dari animasi yaitu menggerakkan benda mati seolah-olah hidup, visi gerak yang diterapkan pada benda mati, dan 
tampilan yang cepat dari urutan gambar-gambar 2D ataupun 3D atau model dalam posisi tertentu, untuk menciptakan ilusi gerak. (Gumelar, 2011).

Untuk dapat membuat animasi tiga dimensi diperlukan sebuah perangkat lunak. Autodesk 3dsMax atau sebelumnya 3D Studio Max merupakan salah satu perangkat lunak yang banyak digunakan dalam proses pembuatan film animasi 3 dimensi. Dengan perangkat lunak ini, pengguna dapat membuat animasi 3 dimensi, model, permainan, dan gambar. Secara umum, untuk dapat membuat sebuah animasi 3 dimensi ada beberapa tahap yang dapat dilakukan, yaitu: modelling, texturing, rigging, animation, dan rendering (Autodesk, 2014).

Menurut Tavangarian, dkk (2004), e-learning merupakan sistem pembelajaran elektronik yang mencakup berbagai jenis media yang dapat memberikan dan menampilkan teks, audio, gambar, animasi, dan video streaming, dan termasuk aplikasi teknologi dan proses seperti audio atau video tape, TV satelit, CD-ROM, dan pembelajaran berbasis komputer, baik menggunakan intranet, extranet atau berbasis website. Dari pernyataan tersebut, dapat disimpulkan bahwa e-learning memiliki kelebihan dibandingkan sistem konvensional yaitu, menghemat waktu proses belajar mengajar, mengurangi biaya perjalanan, menjangkau wilayah geografis yang lebih luas, dan sebagainya. (Hannay \& Newvine, 2006). Namun, di samping kelebihan e-learning yang sudah dipaparkan tersebut, e-learning memiliki 2 (dua) masalah yang biasanya terjadi dari sisi penggunanya, yaitu kurangnya motivasi dan waktu (Visser, dkk, 2002).

Menurut penelitian Lee dan Hammer (2011), game dapat memberikan 3 (tiga) keuntungan psikologi, yaitu kognitif, emosional, dan sosial sehingga dapat meningkatkan motivasi pemain dalam mempelajari suatu game. Kurangnya motivasi pengguna untuk menggunakan e-learning, dapat berakibat berkurangnya motivasi untuk belajar. Salah satu teknik yang dapat mengatasi masalah kurangnya motivasi dengan memenuhi kebutuhan manusia yaitu dengan menerapkan elemen rancangan yang ada dalam game pada desain sistem informasi untuk e-learning yang akan dibangun, atau yang lebih dikenal dengan gamifikasi. 
Gamifikasi adalah sebuah proses yang bertujuan mengubah non-game context (contoh: belajar, mengajar, pemasaran, dan lain sebagainya) menjadi jauh lebih menarik dengan mengintegrasikan game thinking, game design, dan game mechanics (Takasahi, 2010). Meer (2013) telah melakukan sebuah penelitian tentang dampak penggunaan e-learning dengan metode gamifikasi berjudul "User Experience of Gamification in E-Learning“. Dari penelitian yang dilakukan dihasilkan kesimpulan bahwa penggunaan komponen dalam game (penerapan gamifikasi) ke dalam e-learning cukup mempengaruhi user dalam mempelajari materi, dan hal ini tergantung dari tipe user dan jenis atau komponen game yang digunakan dalam e-learning tersebut.

Berkaitan dengan perkembangan animasi 3 dimensi yang begitu pesat, penulis bermaksud mengambil sebuah penelitian tentang bagaimana mempelajari pembuatan animasi 3 dimensi dari mulai tahap modelling sampai dengan animation menggunakan sebuah sarana e-learning dengan konsep gamifikasi. Penggunaan e-learning dimaksudkan agar sistem/ aplikasi yang penulis bangun dapat digunakan oleh banyak pihak yang tertarik mempelajari animasi 3 dimensi tanpa harus bertatap muka ketika kegiatan belajar mengajar berlangsung. Penggunaan metode gamifikasi digunakan sebagai salah satu inovasi baru dalam mempelajari animasi 3D.

\section{METODE PENELITIAN}

Metode yang digunakan dalam penelitian ini adalah metode penelitian dan pengembangan atau Research and Development $(\mathrm{R} \& \mathrm{D})$, yaitu metode penelitian yang digunakan untuk menghasilkan produk tertentu, dan menguji kefektifan produk tersebut (Sugiyono, 2010).

Menurut Sugiyono (2010), langkah-langkah penelitian R \& D terdiri dari 10 langkah sebagai berikut:
a. Potensi dan Masalah
f. Ujicoba Produk
b. Pengumpulan Data
g. Revisi Produk
c. Desain Produk
h. Ujicoba Pemakaian
d. Validasi Desain
i. Revisi Produk
e. Revisi Desain
j. Produksi Masal 
Pada penelitian ini langkah-langkah Research and Development (R\&D) disesuaikan dengan menyederhanakannya menjadi tujuh langkah seperti terlihat pada gambar 2

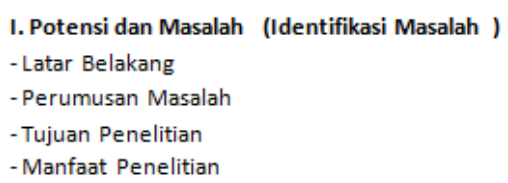

IV. Uji Coba Produk (Evaluasi Sistem) Pengujian sistem menggunakan metode white box dan black box testing
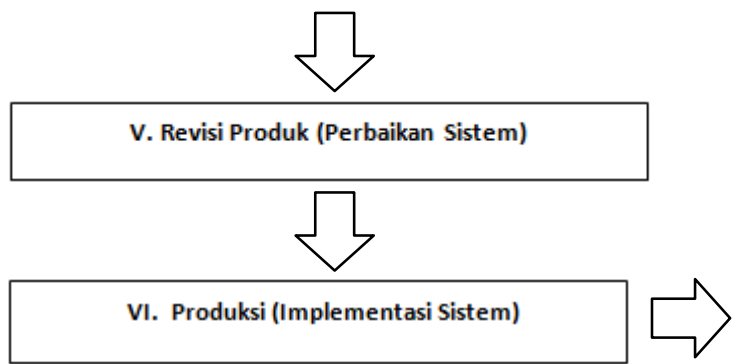

II. Pengumpulan Data

- Literatur

- Observasi

- Dokumentasi

III. Desain Produk

a. Analisa

- Analisa Data

- Analisa Kebutuhan Sistem

- Analisa Gamifikasi (MDA Framework)

b. Perancangan Sistem

Perancangan e-learning dengan konsep gamifikasi dengan menggunakan MDA framework

Gambar 2. Alur Penelitian (Adaptasi Alur Penelitian R \& D Sugiyono)

\section{HASIL DAN PEMBAHASAN}

Penelitian ini khusus mengambil tema tentang animasi 3D, materi yang akan diberikan pada sistem yang akan dibangun ini meliputi pembuatan model 3D (Modeling), Material \& Texturing, Rigging \& Skinning, Animation, dan Rendering menggunakan software Autodesk 3ds Max. Tiap materi / topic disusun dengan menggunakan konsep gamifikasi.

\section{Analisis Data}

Analisis data adalah proses penyederhanaan data dalam bentuk yang lebih mudah dibaca dan diinterpretasikan. Penelitian ini menggunakan metode triangulasi data (data triangulation) dimana data-data yang digunakan diambil 
dari beragam sumber untuk memperoleh kebenaran informasi yang handal dan gambaran yang utuh tentang penerapan konsep gamifikasi dalam e-learning yang digunakan untuk mempelajari animasi 3D.

Adapun langkah-langkah analisis data yang dilakukan adalah sebagai berikut:

a. Setelah data terkumpul, peneliti mengadakan reduksi data dengan merangkum data yang dibutuhkan, mencatat hal-hal pokok yang relevan dengan focus penelitian.

b. Menyusun secara sistematik berdasarkan kategori dan klasifikasi tertentu.

c. Menyajikan temuan ke dalam sistem.

\section{Analisis Fungsional Sistem}

Analisis kebutuhan fungsional system sangat dibutuhkan dalam mendukung kinerja sistem. Berikut adalah kebutuhan fungsional system e-learning gamifikasi Animasi 3D.

a. Admin; mempunyai hak akses dalam keseluruhan sistem.

b. Pengajar; system memberikan hak kepada pegajar untuk mengunggah materi dan menambahkan soal/ kuis.

c. Guest; atau tamu hanya dapat melihat halaman utama website tanpa dapat mengikuti kursus yang telah disediakan.

d. User

1) Sistem memberikan hak kepada user untuk melakukan proses pendaftaran/registrasi online dan dapat menampilkan profile user

2) Sistem dapat menampilkan materi, memberikan hak untuk mengikuti kuis

3) Sistem dapat mengacak soal pada kuis

4) Sistem dapat menampilkan skor/poin, menampilkan badge yang diperoleh oleh user dan dapat menampilkan leaderboard.

5) Sistem dapat menampilkan recent activity yang merupakan progress terhadap materi/kuis yang telah diikuti oleh user.

\section{Analisis Gamifikasi}

Analisis gamifikasi merupakan tahapan bagaimana menganalisa gamifikasi yang akan diterapkan pada sistem. Dalam analisis ini penulis menggunakan MDA framework sebagai acuan. MDA (Mechanics, Dynamics, danAesthetic) framework merupakan framework yang digunakan untuk desain sebuah game.

a. Mechanics: merupakan komponen yang mampu menggerakkan pemain untuk melakukan suatu aksi. Game mekanik yang digunakan dalam system ini diuraikan sebagai berikut: 
1) Points; setiap pemain yang telah berhasil melakukan beberapa tugas yang diberikan oleh system berhak mendapatkan poin yang besarannya sudah ditentukan oleh sistem.

2) Levels; digunakan sebagai sarana untuk menunjukan perkembangan dari seorang pemain.

3) Leaderboard; digunakan sebagai fasilitas untuk membandingkan pencapaian satu pemain dengan pemain lainnya. Penggunaan leaderboard juga bertujuan untuk memotivasi pemain agar selalu merasa tertantang untuk menjadi yang terbaik.

4) Badges; setiap pemain yang berhasil melakukan tugas tertentu akan mendapatkan badges. Selain itu badges juga berfungsi untuk menunjukan level pemain.

5) Challenge / Quest; digunaka noleh system untuk memberikan tantangan dan memberikan petunjuk pada pemain mengenai yang dapat dilakukan untuk dapat melanjutkan ke level yang lebih tinggi. Tantangan dalam system ini disajikan dalam bentuk quiz yang harus diselesaikan oleh pemain pada tiap akhir topic materi.

6) On boarding; merupakan sebuah upaya untuk membantu pemain pemula yang masuk ke dalam game. Gamifiedsystem yang baik akan memberikan sedikit opsi di awal kemudian berangsur opsi tersebut bertambah berjalannya waktu (level pemain). Penerapan on boarding dalam system ini disajikan saat pemain pertama kali memulai pembelajaran. Tujuannya untuk memberikan gambaran tentang bagaimana proses belajar menggunakan system ini.

b. Dynamics: merupakan interaksi pemain dengan mechanics itu sendiri. Dynamics menentukan apa yang terjadi dengan pemain ketika mechanics bekerja.

c. Aesthetics: merupakan harapan respon emosi dari pemain ketika menggunakan game tersebut. Perasaan/emosi seperti joy, frustration, fantasy, fellowship (sukacita, frustrasi, fantasi, persahabatan). Dengan menggunakan system ini diharapkan pemain/pengguna dapat merasakan efek gamifikasi seperti perasaan suka cita ketika mampu mengerjakan tugas dengan cepat dan tepat, frustasi ketika poin yang didapat lebih kecil dari pemain lain, fantasi untuk dapat meningkatkan skill dan menyelesaikan tugas/tantangan dengan lebih cepat dan tepat, serta persahabatan yang timbul antar pemain dengan adanya fitur leaderboard. 


\section{Rancangan Proses}

Rancangan proses untuk sistem yang dibangun menggunakan use case diagram. Use case diagram digunakan sebagai translasi dari kebutuhan fungsional sistem yang akan dibangun.

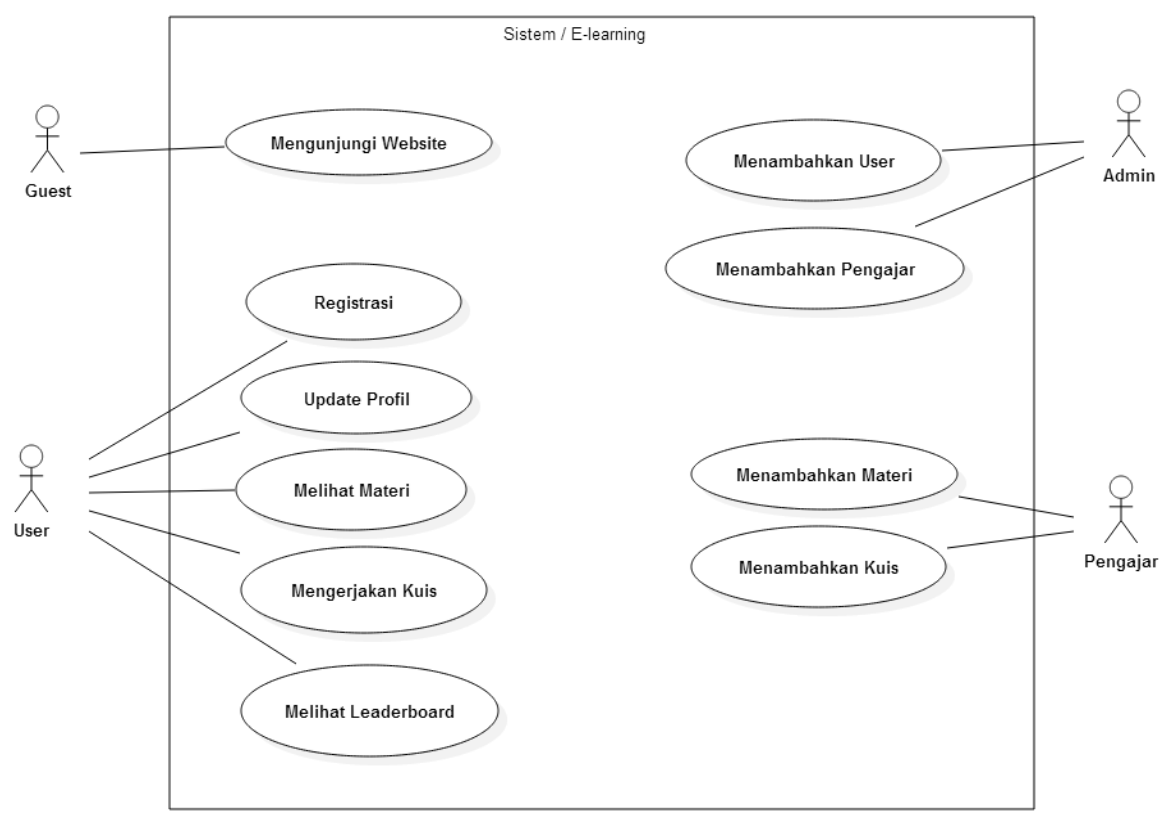

Gambar4. Use case diagram system pembelajaran Animasi 3D

\section{Rancangan Gamifikasi}

Tabel 2.Rancangan Gamifikasi

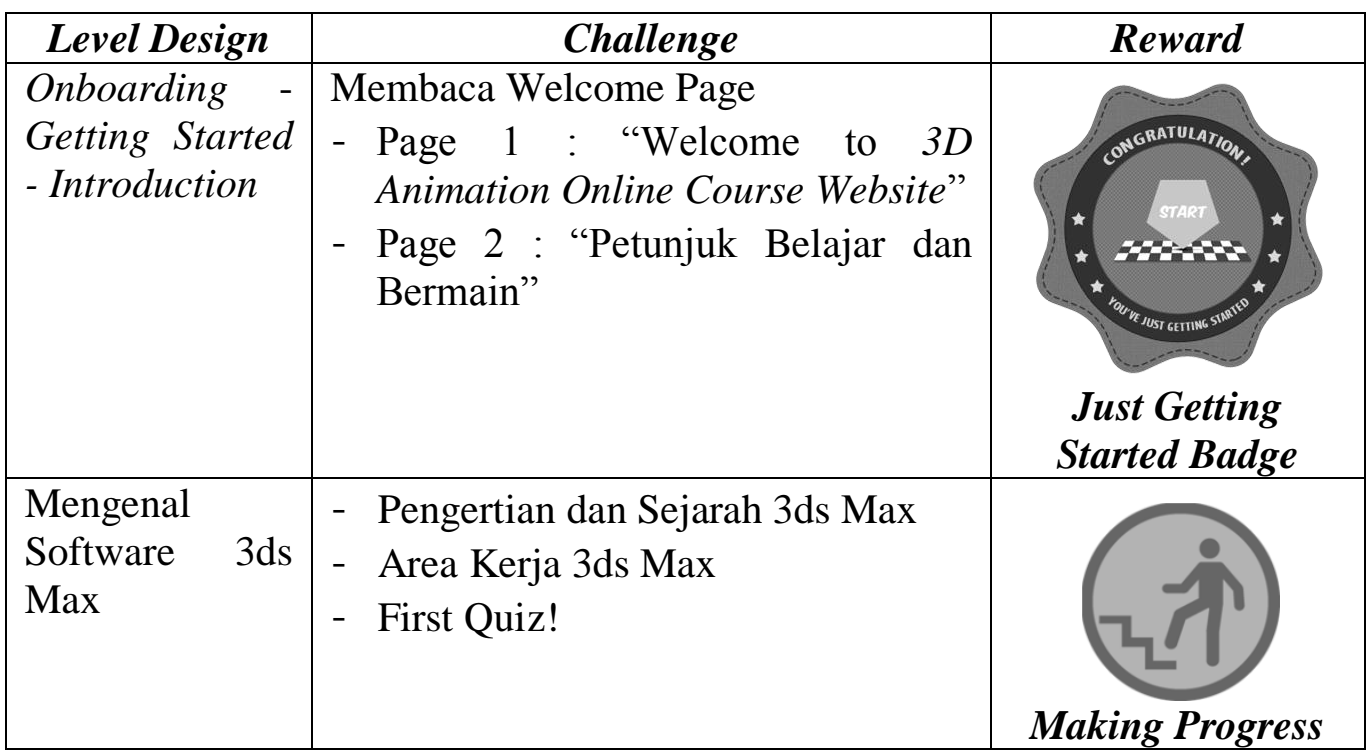




\begin{tabular}{|l|l|l|}
\hline & & Badge \\
\hline Topik 1 & - Sub Object 3D Modeling & \\
Modeling 3D & - Teknik 3D Modeling & \\
& - 3D Modeling - Tutorial & 3D Modeling Quiz! \\
& & $\begin{array}{c}\text { Course Completion } \\
\text { Tsopic }\end{array}$ \\
\hline
\end{tabular}

Tabel 2. Rancangan Gamifikasi (lanjutan)

\begin{tabular}{|c|c|c|}
\hline Level Design & Challenge & Reward \\
\hline $\begin{array}{l}\text { Topik } 2- \\
\text { Texturing }\end{array}$ & $\begin{array}{l}\text { - } \text { Material Object } \\
\text { - Cara Memberikan Material } \\
\text { - Efek-efek Material } \\
\text { - Basic Material Map Types - } \\
\text { Tutorial } \\
\text { - Material \& Texturing Quiz! }\end{array}$ & $\begin{array}{l}\text { mpletion } \\
\text { pic }\end{array}$ \\
\hline $\begin{array}{lll}\text { Topik } & 3 & - \\
\text { Rigging } & & \end{array}$ & $\begin{array}{l}\text { - } \text { Mengenal Bones \& Biped untuk } \\
\text { Rigging Object } \\
\text { - Bones Rigging Tutorial } \\
\text { - Biped Rigging Tutorial } \\
\text { - Rigging Quiz! }\end{array}$ & $\begin{array}{c}\text { Course Completion } \\
3^{\text {rd }} \text { Topic }\end{array}$ \\
\hline $\begin{array}{l}\text { Topik } 4- \\
\text { Animation }\end{array}$ & $\begin{array}{l}\text { - } \text { Pengertian Animasi } \\
\text { - Jenis-Jenis Animasi } \\
\text { - } 12 \text { Prinsip Utama pada Animasi } \\
\text { - } 3 \text { D Text Animation - Tutorial } \\
\text { - } \text { Walking Animation - Tutorial } \\
\text { - }\end{array}$ & $\begin{array}{r}\text { Course } \\
4^{t}\end{array}$ \\
\hline $\begin{array}{l}\text { Topik } 5 \\
\text { Rendering }\end{array}$ & $\begin{array}{l}\text { - } \text { Pengertian } \\
\text { - } \text { Metode Rendering } \\
\text { - Render File Image pada 3ds Max - } \\
\text { Tutorial } \\
\text { - Render File Movie pada 3ds Max - } \\
\text { Tutorial } \\
\text { - } \text { Rendering Quiz! }\end{array}$ & $\begin{array}{r}\text { Course } C \\
5^{\text {th }} 7\end{array}$ \\
\hline Final Quiz & $\begin{array}{l}\text { - Quiz terakhir yang berisi materi } \\
\text { dari topic } 1 \text { s.d } 5\end{array}$ & \\
\hline
\end{tabular}


Tabel 3. Tabel Aktivitas Lain yang Menghasilkan Poin dan Badge

\begin{tabular}{|c|c|c|}
\hline No. & Aktivitas & Reward \\
\hline 1. & $\begin{array}{l}\text { Update data diri } \\
\text { (profil) }\end{array}$ & \\
\hline & & Update Profile Badge \\
\hline
\end{tabular}

\section{Implementasi Sistem}

Implementasi merupakan tahap penerapan system berdasarkan analisis dan rancangan sistem yang telah dipaparkan sebelumnya. Sistem yang dibangun dirancang dengan menggunakan LMS (Learning Management System).

\section{a. Halaman Utama}

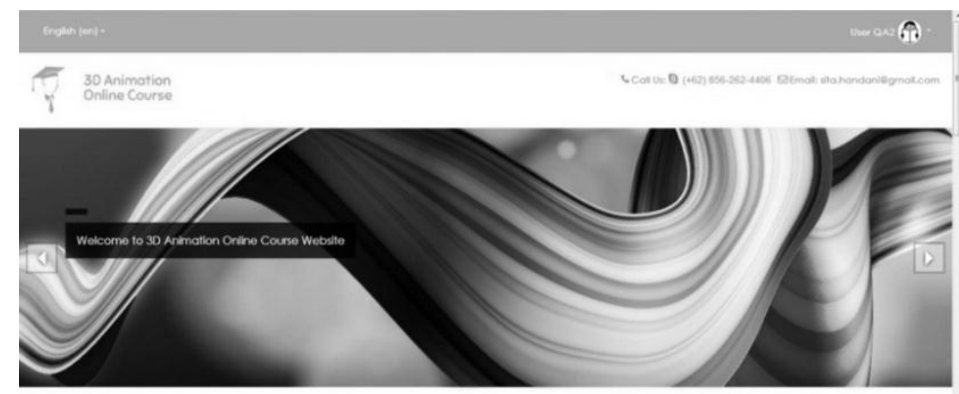

Avallable courses

Gntting Statind

Gambar 10. Halaman Utama

\section{b. Halaman Registrasi User}

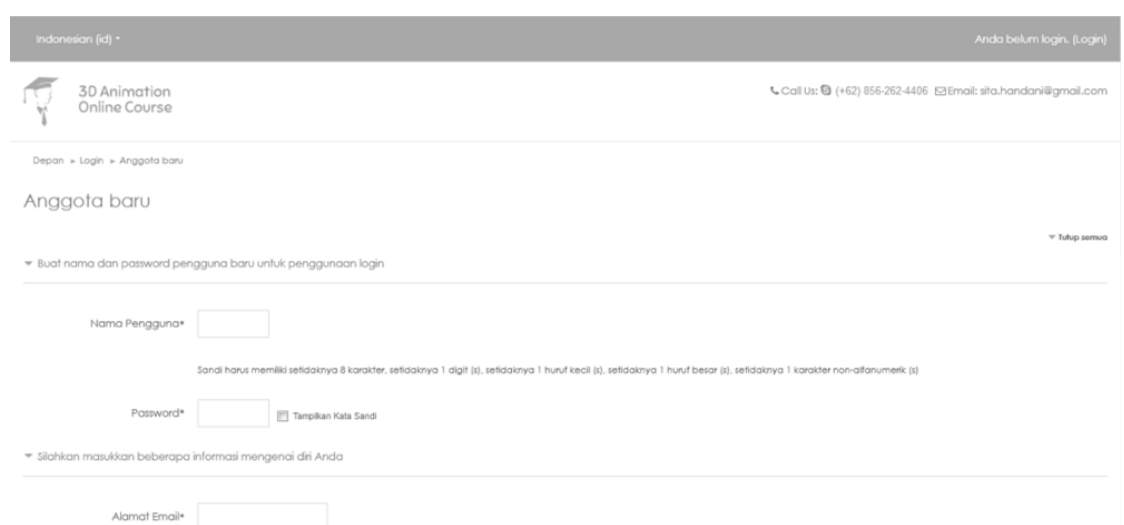

Gambar 11. Halaman Registrasi User 


\section{c. Halaman Quiz}

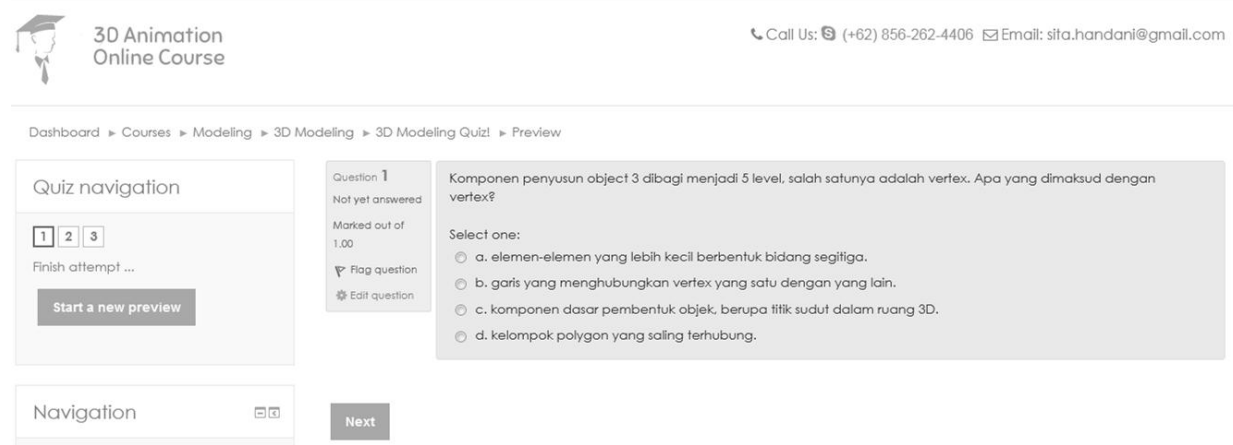

Gambar12.Halaman Quiz

\section{d. HalamanProfil User}

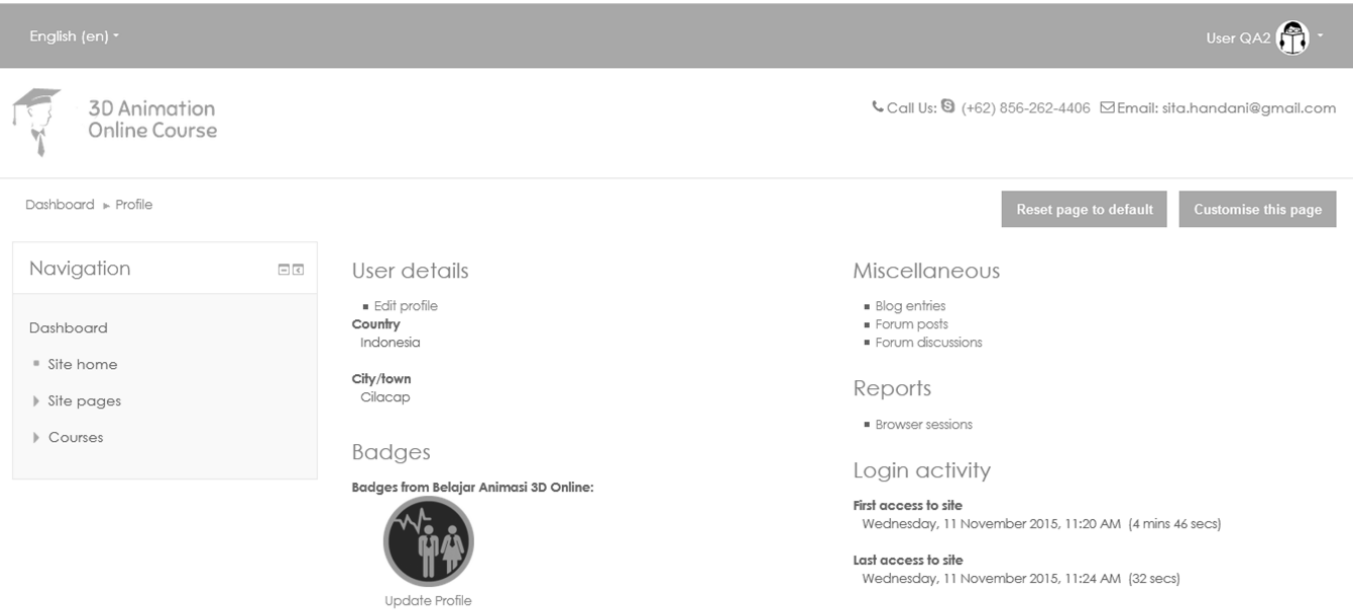

Gambar13. Halaman Profil User

\section{e. Halaman Leaderboard / Ranking}

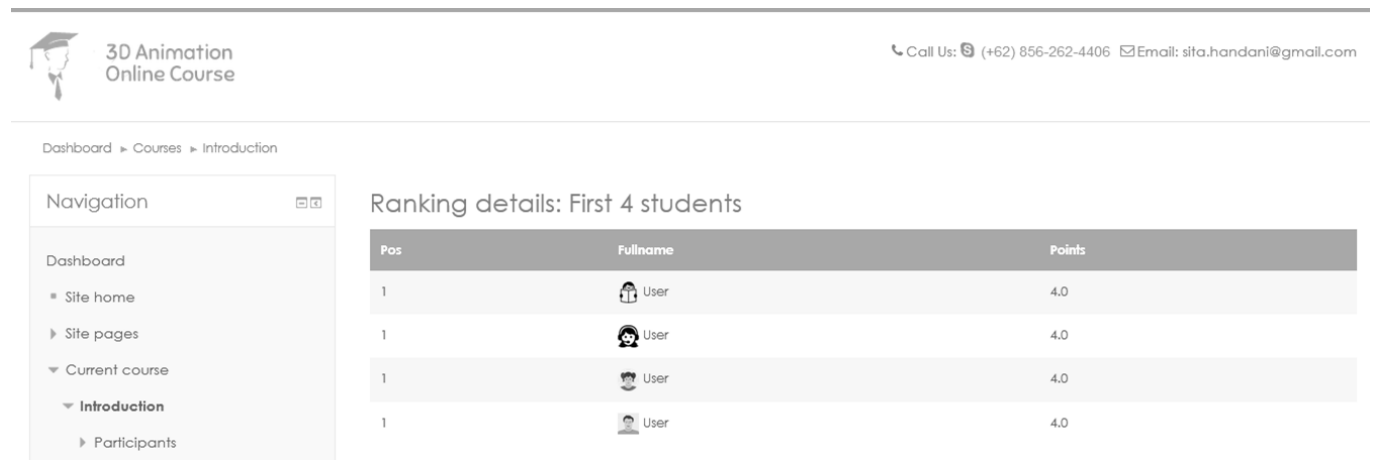

Gambar 14.Halaman Leaderboard / Ranking 


\section{KESIMPULAN DAN SARAN}

\section{Kesimpulan}

Berdasarkan pada hasil implementasi dan pengujian dari penerapan konsep gamifikasi pada e-learning untuk pembelajaran Animasi 3D dapat disimpulkan beberapa hal sebagai berikut:

a. Konsep gamifikasi berhasil diterapkan ke dalam sistem/e-learning dengan menggunakan MDA (Mechanic, Dynamic, Aesthetic) framework.

b. Untuk menentukan target pemain, peneliti menggunakan Richard Bartle's teori dalam menyusun gamifikasi ke dalam sistem/e-learning.

c. Materi Animasi 3D yang disajikan dalam sistem/e-learning didesain menjadi beberapa level untuk mempermudah pengguna dalam mempelajari Animasi 3D dari tahap Modelingsampai dengan Rendering.

\section{Saran}

Ada beberapa saran dari peneliti untuk pengembangan penerapan konsep gamifikasi pada $e$-learning untuk pembelajaran Animasi 3D, yaitu:

a. Penerapan konsep gamifikasi pada e-learning untuk pembelajaran Animasi 3D masih terbatas pada pengujian secara fungsional sistem, belum dilakukan pengujian dari sisi user experience, untuk penelitian berikutnya dapat dikembangkan lagi dengan melakukan pengujian / evaluasi dari sisi pengalaman pengguna.

b. Materi yang terdapat dalam sistem ini masih sangat terbatas dan hanya dicontohkan dengan tutorial menggunakan software 3ds Max, untuk penelitian berikutnya dapat dikembangkan lagi dengan menambahkan kategori software dan tingkat kesulitan masing-masing topik.

c. Penerapan konsep gamifikasi pada e-learning untuk pembelajaran Animasi 3D masih sangat mungkin untuk terus dikembangkan ke arah yang lebih baik lagi, semisal dengan menjalin kerjasama dengan para profesional di bidang Animasi 3D sehingga membuat materi yang disampaikan lebih berbobot lagi.

d. Penerapan konsep gamifikasi pada e-learning untuk pembelajaran Animasi 3D ini juga dapat diadaptasi ke dalam lingkungan kampus yang mengajarkan mata kuliah Animasi 3D. 


\section{DAFTAR PUSTAKA}

3d Modeling and Rendering Software |3ds Max | Autodesk [WWW Document], n.d. URL http://www.autodesk.com/products/3ds-max/overview. Diakses pada 19November 2014.

Bartle, R. 2011. Player Types and Gamification. Gamification Res. Organ.

Effendi, E., \&Hartono, Z. 2005. E-learning Konsep dan Aplikasi. Yogyakarta: Penerbit Andi.

Gamication.org.

Game

mechanics. http://gamication.org/wiki/EncyclopediaDiakses pada 19November 2015.

Gumelar, M. 2011. 2D Animation, Hybrid Technique: Book A. Jakarta: PT. Indeks.

Hannay, M. \&Newvine, T. 2006. Perceptions of Distance Learning: A Comparison of Online and Traditional Learning. MERLOT J. Online Learn. Teach.

Hunicke, R.; LeBlanc, M., Zubek, R. 2004. MDA: A Formal Approach to Game Design and Game Research. Proc. Chall. Game AI Workshop.

Lee, J.J; Hammer, J. 2011. Gamification in Education: What, How, Why Bother? Acad. Exch. Q. 152.

Meer, R. 2013. User Experience of Gamification in E-Learning. Maastricht University.

Schmidt, F.M. 1999. Building Application Frameworks: Object-Oriented Foundations of Frameworks Design, 5th ed.New York: John Wiley \& Sons, Inc.

Sugiyono. 2010. Metode Penelitian Pendidikan: Pendekatan Kuantitatif, Kualitatif, dan R\&D, 11th ed. Bandung: Alfabeta.

Sonts, K. 2013. Gamification in Higher Education The Case Study on the "Game Interactions" Course. Tallinn University.

Takahashi, D. 2010. Gamification Gets Its Own Conference. Venture Beat.

Tavangarian, D., Leypold, M.E., Nölting, K., Röser, M., Voigt, D. 2004. Is Elearning the Solution for Individual Learning?. J. E-Learn. EJEL.

Vaughan, Tay. 2011. Multimedia: Making It Work Eighth Edition. New York: McGraw-Hill.

Vestad, Erlend Larsen., 2013. Creating a Gamified LearningPlatform to Teach University Curriculum in Programming. Department of Informatics, University of Oslo.

Xu, Y. 2012. Web Application Gamification and Analytics. University of Hawai,,i Honolulu, HI. 